Article

\title{
On the Investigation of Microstructured Charcoal as an ANFO Blasting Enhancer
}

\author{
Suzana Gotovac Atlagic $1, *$, Andrzej Biessikirski ${ }^{2, *} \mathbb{C}$, tukasz Kuterasiński ${ }^{3, *}$, \\ Michał Dworzak ${ }^{2}$, Michał Twardosz ${ }^{2}$, Niki Sorogas 4 (D) and John Arvanitidis 4 (D) \\ 1 Faculty of Natural Sciences and Mathematics, University of Banja Luka, Mladena Stojanovića 2, \\ 78000 Banja Luka, Bosnia and Herzegovina \\ 2 Faculty of Mining and Geoengineering, AGH University of Science and Technology, Al. Mickiewicza 30, \\ 30-059 Kraków, Poland; dworzak@agh.edu.pl (M.D.); michaltw@agh.edu.pl (M.T.) \\ 3 Jerzy Haber Institute of Catalysis and Surface Chemistry, Polish Academy of Sciences, ul. Niezapominajek 8, \\ 30-239 Kraków, Poland \\ 4 Physics Department, Aristotle University of Thessaloniki, 54124 Thessaloniki, Greece; \\ nsorogka@physics.auth.gr (N.S.); jarvan@physics.auth.gr (J.A.) \\ * Correspondence: suzana.gotovac.atlagic@unibl.org (S.G.A.); abiess@agh.edu.pl (A.B.); \\ nckutera@cyf-kr.edu.pl (Ł.K.); Tel.: +48-12-67-20-70 (A.B.); +48-12-6395-115 (Ł.K.)
}

Received: 26 July 2020; Accepted: 25 August 2020; Published: 9 September 2020

check for updates

\begin{abstract}
In this study, we examined the influence of microstructured charcoal (MC) when added to ammonium nitrate fuel oil (ANFO) samples. We performed a study that investigated ANFOs structure, crystallinity, and morphology by utilizing infrared spectroscopy (IR), X-ray diffraction (XRD), and scanning electron microscopy (SEM), respectively. MC characteristics were probed by Raman spectroscopy and SEM analysis. SEM analysis indicated how fuel oil (FO) covered ammonium nitrate prill. Moreover, the surface of the MC was covered by specific microfibers and microtubes. The disordered graphitic structure of the MC was also confirmed by Raman spectroscopy. Simulation of blasting properties revealed that the addition of MC should decrease blasting parameters like heat explosion, detonation pressure, and detonation temperature. However, the obtained differences are negligible in comparison with the regular ANFO. All analyses indicated that MC was a good candidate as an additive to ANFO.
\end{abstract}

Keywords: ANFO; charcoal; morphology; SEM

\section{Introduction}

Ammonium nitrate fuel oil (ANFO) is one of the most commonly used mining explosives in the world [1]. This might be explained by its low cost and production simplicity, as well as by its good blasting parameters. However, ANFO is also considered as a non-ideal explosive due to its non-ideal detonation behavior. This means that it cannot reach its theoretically predicted values, like the velocity of detonation (VOD) [2].

From a chemical point of view, ANFO is a mixture of ammonium nitrate (recommended porous prill type) with fuel oil (FO) in a weight ratio of 94.5:5.5 that allows for the obtainment of a zero oxygen balance. The zero oxygen balance determines the highest energy value and lowest volume of toxic fumes. However, some additives like various types of metals (e.g., aluminum) can be applied to improve blasting parameters. The application of additives influences the reaction zone that results in a change in the Chapman-Jouguet plain. However, we applied new component results when changing the oxygen balance. The same thing can be assigned when applying various types of fuel oil. Besides an influence on oxygen balance, fuel components have an impact on explosive sensitivity [3]. Improved 
sensitivity results in an increased ability of detonation. However, applying some fuels or various additives can decrease sensitivity, which should result in deflagration or misfire.

Chemical explosives (including ANFO) with suitable initiation are subjected to rapid decomposition, matter expansion, and heat and gas production.

Oxley et al. [4,5] indicated that the mechanism of AN decomposition is characterized by both a radical and an ionic reaction. The former reaction is at a high rate and takes place at high temperatures. The opposite effect can be observed for the latter reaction, for which the rate and temperature are low. The melting point of $\mathrm{AN}$ is $169^{\circ} \mathrm{C}$ and thus $\mathrm{AN}$ decomposition is possible. According to Brower et al. [6], at the beginning of a radical reaction, $\mathrm{AN}$ undergoes dissociation to $\mathrm{HNO}_{3}$ and $\mathrm{NH}_{3}$ (Equation (1)), and subsequently the homolysis of the $\mathrm{O}-\mathrm{N}$ bond in $\mathrm{HNO}_{3}$ takes place (Equation (2)). Due to the very high values of $\mathrm{HNO}_{3}$ homolysis activation energy (ca. $190 \mathrm{kJmol}^{-1}$ ), this stage is considered as a rate-controlling step. Wada et al. [7] determined the temperature of $\mathrm{HNO}_{3}$ homolysis as $1300^{\circ} \mathrm{C}$ in the flame.

$$
\begin{gathered}
\mathrm{NH}_{4} \mathrm{NO}_{3} \leftrightarrow \mathrm{NH}_{3}+\mathrm{HNO}_{3} \\
\mathrm{HNO}_{3} \rightarrow * \mathrm{OH}+\mathrm{NO}_{2}
\end{gathered}
$$

In next step, the high-rate radical chain reaction occurs according to Equations (3) and (4).

$$
\begin{gathered}
\mathrm{NH}_{3}+{ }^{*} \mathrm{OH} \rightarrow \mathrm{NH}_{2}+\mathrm{H}_{2} \mathrm{O} \\
\mathrm{NH}_{2}+\mathrm{NO}_{2} \rightarrow\left[\mathrm{NH}_{2} \mathrm{NO}_{2}\right] \rightarrow \mathrm{N}_{2} \mathrm{O}+\mathrm{H}_{2} \mathrm{O}
\end{gathered}
$$

In the case of $\mathrm{NH}_{4} \mathrm{NO}_{3}$ ionic reaction, the process begins by the dissociation of $\mathrm{AN}$ into $\mathrm{NH}_{3}$ and $\mathrm{HNO}_{3}$ (Equation (1)). In the next step, $\mathrm{NH}_{3}$ oxidation occurs by the products from $\mathrm{HNO}_{3}$ decomposition (Equations (5)-(7)).

$$
\begin{gathered}
2 \mathrm{HNO}_{3} \rightarrow \mathrm{NO}_{2}+\mathrm{NO}_{3}^{-} \\
\mathrm{NO}_{2}+\mathrm{NO}_{3}^{-} \rightarrow \mathrm{NO}_{2}{ }^{+}+\mathrm{NO}_{3}^{-} \\
\mathrm{NO}_{2}{ }^{+}+\mathrm{NH}_{3} \leftrightarrow\left[\mathrm{NH}_{3} \mathrm{NO}_{2}\right]^{+} \rightarrow \mathrm{N}_{2} \mathrm{O}+\mathrm{H}_{2} \mathrm{O}
\end{gathered}
$$

Bare powders are not able to hold a shape and TNT is often added to enable the formation of melt-castable explosives. According to the existing literature, most of the explosive powders are subjected to plasticization in order to obtain a moldable material. The addition of FO, icing sugar, or aluminum leads to explosive formation at a higher heat and mass release, as well as materials characterized by faster expansion [8].

The applicability of various flammable components has been previously investigated $[9,10]$. Sinditskii et al. concluded that the content of the flammable component, like charcoal, 2,4,6-trinitrotoluene, fuel oil (diesel), or iron persulfide (II), is indispensable during the detonation process [9]. Gunawan and Zhang noticed that the presence of pyrite in ANFOs chemical composition additionally catalyzes the decomposition reaction of an explosive [10]. The influence of the flammable component on the blasting properties of ANFO has also been studied [11-24]. In the conducted research, the combustible components were coal dust, sugar in the powdered and crystalline forms, aluminum dust, 2,4,6-trinitrotoluene, and fuel oil.

Another example of a component added to AN used to obtain explosives is inorganic carbon. Reiset and Millon [16] indicated that the explosion of AN can occur in the presence of red-hot charcoal or as a result of heating an AN-charcoal mixture to $170{ }^{\circ} \mathrm{C}$. In turn, Izato et al. [17] investigated the influence of carbon on AN decomposition. It was found that neither graphite nor carbon black influenced the studied reaction. It was also shown that adding nanoparticle carbon black powders 
or activated carbon (AC) caused the onset temperature of AN decomposition to lower. The process occurs mainly according to the ionic mechanism, as follows. In the liquid phase:

$$
\begin{gathered}
\mathrm{NO}_{2}{ }^{+}+\mathrm{C} \rightarrow \mathrm{CO}_{2}+1 / 2 \mathrm{~N}_{2} \\
\mathrm{NO}_{3}{ }^{-}+1 \frac{1}{2} \mathrm{C} \rightarrow 1 \frac{1}{2} \mathrm{CO}_{2}+1 / 2 \mathrm{~N}_{2}
\end{gathered}
$$

In the gaseous phase:

$$
2 \mathrm{~N}_{2} \mathrm{O}+\mathrm{C} \rightarrow \mathrm{CO}_{2}+2 \mathrm{~N}_{2}
$$

It must be emphasized that the reactions between $\mathrm{AN}$ and fuel may occur at temperatures lower than the melting point of AN $\left(169.6^{\circ} \mathrm{C}\right)$. Hussain and Rees [18] indicated the presence of a distinct and exothermic peak at $185^{\circ} \mathrm{C}$ for the mixture of AN and charcoal. For comparison, in the case of pure AN, no exothermic peaks were found at the same temperature other than at $140^{\circ} \mathrm{C}$. Lurie and Chang [19] indicated that the introduction of carbon black into AN resulted in the lowering of AN decomposition temperature to $70{ }^{\circ} \mathrm{C}$. The process can be described by (Equation (11)), in which $\mathrm{HNO}_{3}$ decomposition is crucial:

$$
\mathrm{HNO}_{3}+\mathrm{C}_{6} \rightarrow \mathrm{C}_{5}-\mathrm{C}=\mathrm{O}+\mathrm{HNO}_{2}
$$

Subsequently, $\mathrm{C}_{5}-\mathrm{C}=\mathrm{O}$ undergoes oxidation into intermediates in the form of ions and radicals. Furthermore, the formation of low stability ammonium nitrite $\left(\mathrm{NH}_{4} \mathrm{NO}_{2}\right)$ allows for the production of $\mathrm{CO}$ and $\mathrm{N}_{2}[15,20,21]$ :

$$
\begin{gathered}
2 \mathrm{NH}_{4} \mathrm{NO}_{3}+\mathrm{C} \rightarrow \mathrm{CO}_{2}+2 \mathrm{NH}_{4} \mathrm{NO}_{2} \\
\mathrm{NH}_{4} \mathrm{NO}_{2} \rightarrow \mathrm{N}_{2}+2 \mathrm{H}_{2} \mathrm{O}
\end{gathered}
$$

Miyake et al. [22] performed DSC experiments for AN and AC blends. It was evidenced that a small amount of $\mathrm{AC}(4 \% \mathrm{wt}$.) in the AN-AC mixture did not notably change heat production, but rather caused a shift in the exothermic peak towards a lower temperature $\left(310{ }^{\circ} \mathrm{C} \rightarrow 200^{\circ} \mathrm{C}\right)$. Further increase of AC content from $7 \%$ to $10 \%$ wt. led to a significant growth of heat flow $(7 \mathrm{~W} / \mathrm{g} \rightarrow 105 \mathrm{~W} / \mathrm{g})$, with a simultaneous decrease of the exothermic peak temperature $\left(200{ }^{\circ} \mathrm{C} \rightarrow 180{ }^{\circ} \mathrm{C}\right)$. Further increase of the amount of AC did not significantly alter DSC results. For high AC content, the temperatures of exothermic peaks were only slightly higher than the melting point $\left(169.6^{\circ} \mathrm{C}\right)$. Miyake et al. [22] also indicated that 7\% wt. of AC in the AN-AC system is stoichiometric. Furthermore, they performed measurements in a pressure vessel $(200 \mathrm{~mL})$ with $1 \mathrm{~g}$ of samples (with various AC contents) at raising temperatures up to $400{ }^{\circ} \mathrm{C}$ and a temperature ramp of $35^{\circ} \mathrm{C} / \mathrm{min}$. During the increase of $\mathrm{AC}$ content from $4 \%$ wt. to $7 \%$ wt., the highest pressure rise was detected $(0.1 \mathrm{MPa} \rightarrow 1.6 \mathrm{MPa})$. Moreover, Izato et al. $[15,23]$ indicated that the type of the applied carbon could also impact the results. In the case of AC, the obtained exothermic effect was the highest, whereas for charcoal and graphite intermediate the effect was the lowest. The obtained results can be explained by the differences in the porous structure of the used carbon.

Adding microstructured charcoal (MC) to the non-ideal explosive's chemical composition should act like an additional fuel component. Moreover, the change in non-ideal explosive density and the influence of MC structure may result in a change of detonation velocity, as well as post-blast fume volume. However, a proper study should confirm the possible application of MC and its impact on non-ideal explosive morphology.

Despite accessing numerous reports concerning ANFO and non-ideal explosives, directly applying MC has not been studied. In this work, we presented the application of a new possible additive. Additionally, the present research shows rare data on the structure of charcoal that is a by-product of dry wood distillation process and is a relatively available material, but was dismissed in the scientific literature due to the overall economic profits determined by other products, such as acidic acid, smoke aromas, etc. The present data shows that this type of carbonized material has a rather complicated though interesting microstructure and a potential as an ANFO additive. 


\section{Materials and Methods}

Ammonium nitrate porous prill (AN-PP) was produced by Yara's International ASA in 2020. It was characterized by a bulk density of $0.82 \mathrm{~g} \cdot \mathrm{cm}^{-3}$ at $20^{\circ} \mathrm{C}$. Prill diameter did not exceed $1 \mathrm{~mm}$. The moisture content was below $0.3 \%$.

Microstructured charcoal (MC) was supplied by the HI Destilacija Teslić in Bosnia and Herzegovina. MC particles had an irregular shape of a diameter in the range of 1-2 $\mathrm{mm}$. MC characteristics are provided in Section 3.1.

Fuel oil (FO) was produced in 2020 by Silesia Oil Sp. z.o.o. At $40{ }^{\circ} \mathrm{C}$, FO was characterized by the density and kinetic viscosity of $0.8 \mathrm{~g} / \mathrm{cm}^{3}$ and $13.6 \mathrm{~mm}^{2} \cdot \mathrm{s}^{-1}$, respectively. We have reported low-temperature properties of FO in one of our previous works [10]. Fuel oil played the role of the flammable component in ANFO.

All ANFO samples were prepared by blending AN-PP with FO for 20 min at $250 \mathrm{rpm}$, using a mixer. MC was added to the ANFO at the last $5 \mathrm{~min}$ of the blending process. All sample compositions are presented in Table 1.

Table 1. Non-ideal explosive compositions, \%wt.

\begin{tabular}{cccc}
\hline Sample Name & AN-PP, \%wt. & FO, \%wt. & MC, \%wt. \\
\hline Sample 1 & 94.5 & 5.5 & - \\
Sample 2 & 94.5 & 4.5 & 1.0 \\
Sample 3 & 94.5 & 2.5 & 3.0 \\
\hline
\end{tabular}

Scanning electron microscopy (SEM) analysis was made using Nova NanoSEM 200 (5-18 keV). Presented micrographs were taken in a range of magnifications of 100-1000×. Before analysis, all non-ideal explosives were dried and coated with a thin carbon layer. Scans were made under low vacuum, ca. $60 \mathrm{~Pa}$, with a low vacuum detector (LVC), operating in secondary electrons mode. The electron beam voltage was $10 \mathrm{kV}$.

The Fourier-transform infrared spectroscopy (FT-IR) measurements were performed in an iS-10 spectrometer (Thermo Scientific, Waltham, MA, USA) by the attenuated total reflectance (ATR) technique. The spectrometer was equipped with an MCT detector. FT-IR measurements were conducted in the wavenumber range of $650-4000 \mathrm{~cm}^{-1}$ with 32 scans per each spectrum.

The crystallinity of the obtained materials was determined using the $X$-ray powder diffraction (XRD) method with a PANalytical X'Pert PRO MPD diffractometer using $\mathrm{CuK} \alpha$ radiation at $40 \mathrm{kV}$ and $30 \mathrm{~mA}$. The XRD experiments were carried out in the $2 \theta$ range of $-50^{\circ}$ with $0.033^{\circ}$ step. The studied ANFO samples were in powder form.

Raman measurements were conducted with a micro-Raman Horiba LabRAM HR spectrometer, equipped with a Peltier-cooled CCD detector. For excitation, the $632.8 \mathrm{~nm}$ line of a He-Ne laser line was focused with a $100 \times$ objective and a power of $0.4 \mathrm{~mW}$ on sample.

Thermodynamic models were established via the ZMWCyw software. The software was developed by the Military University of Technology in Warsaw. Based on the physicochemical properties of individual components, which are included in the ZMWCyw database or input by the user, ZMWCyw software allows for the calculation of non-ideal explosive properties, such as standard energy, explosion pressure, explosion temperature, heat explosion, post-blast volume, and density. The oxygen balance of the non-ideal composition was evaluated based on the standard [25].

\section{Results and Discussion}

\subsection{Microstructured Charcoal Characteristics}

SEM images illustrated in Figure $1 \mathrm{a}, \mathrm{b}$ indicate relative parallel channels and grooves along the MC surface. Closer magnification of $1000 \times$ and $5000 \times($ Figure $1 c, d)$ reveal that the fibrous structures are present at certain places along the surface. This finding indicates that some kind of carbon microfibers 
or microtubes are formed from the cellulose fibrils in this classical process of the dry wood distillation, which has never been reported before. Magnifications of 10,000× and 20,000× show even a more complex structure. Macro- and mesopores were visible (Figure 1e,f). Thickness of the walls, which were visible from the vertical bird view, showed sizes of approximately 50-500 nm. This well-developed structure should contribute to the process of mixing with explosives since more extended surface and maybe even some active sites should be available.

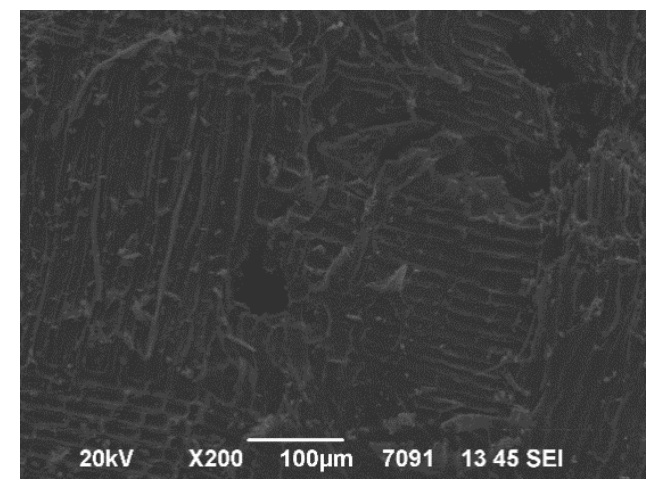

(a)

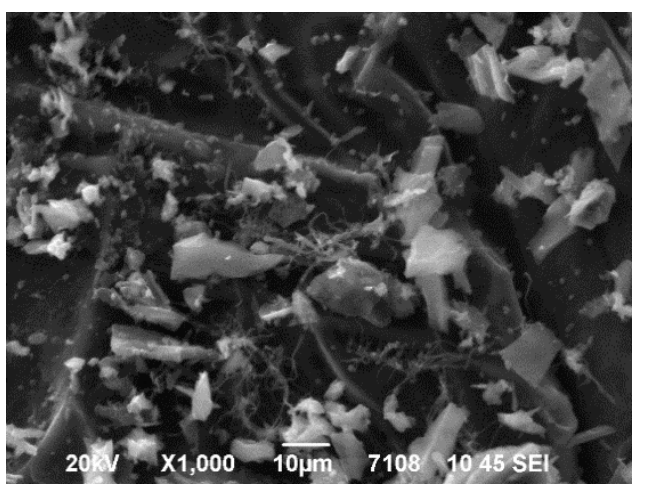

(c)

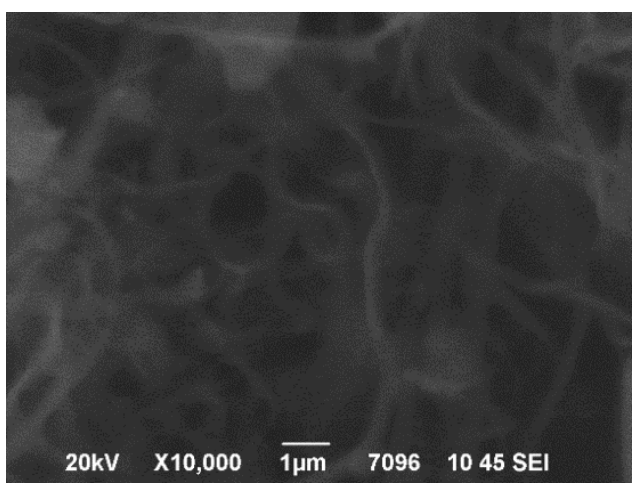

(e)

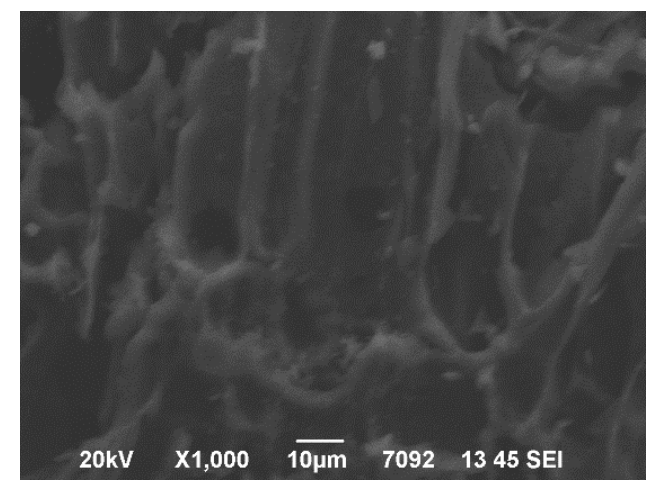

(b)

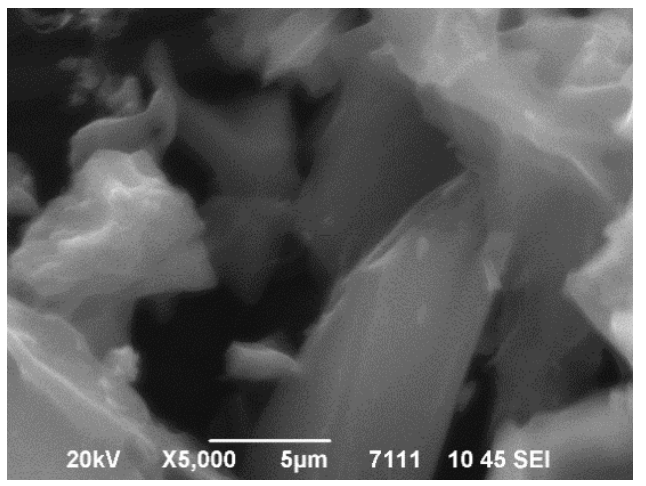

(d)

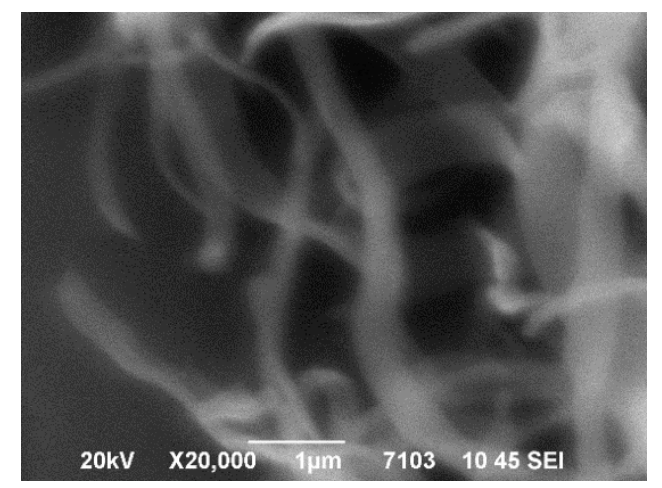

(f)

Figure 1. Scanning electron microscopy (SEM) images of microstructured charcoal (MC) at a magnification of (a) 100×, (b) 1000×, (c) 1000×, (d) 5000× (e) 10,000×, and (f) 20,000×.

Wang et al. [26] also obtained carbon microfibers via wet blending of precursors consisting of cellulose and lignin nanofibrils. The obtained mixture was carbonized at $900{ }^{\circ} \mathrm{C}$. The presence of lignin had a notable impact on the morphology of bicomponent microfibers. Carbon microfibers of high density were characterized by the occurrence of circular cross sections without interfiber fusion. 
The production of carbon microtubes in the presence of Au nanoparticles was reported by Hurtado et al. [27]. In the synthesized systems, the sucrose was applied as a carbon source. It was found that the utilization of sucrose in low concentrations led to the production of carbon microtubes with diameters of $0.8-1.5 \mu \mathrm{m}$. Furthermore, uniform distribution of Au nanoparticles was found.

The Raman spectrum of the sample is illustrated in Figure 2. The so-called G-band, a typical of a stretching vibration of the $\mathrm{sp}^{2}$-hybridized carbon atoms, was observed at $1592 \mathrm{~cm}^{-1}$ and was quite sharp and pronounced. On the other hand, the occurrence of D-band at $1342 \mathrm{~cm}^{-1}$ corresponded to the disordered or $\mathrm{sp}^{3}$-like carbon atoms [27-31], and was rather intense, broad, and asymmetric.

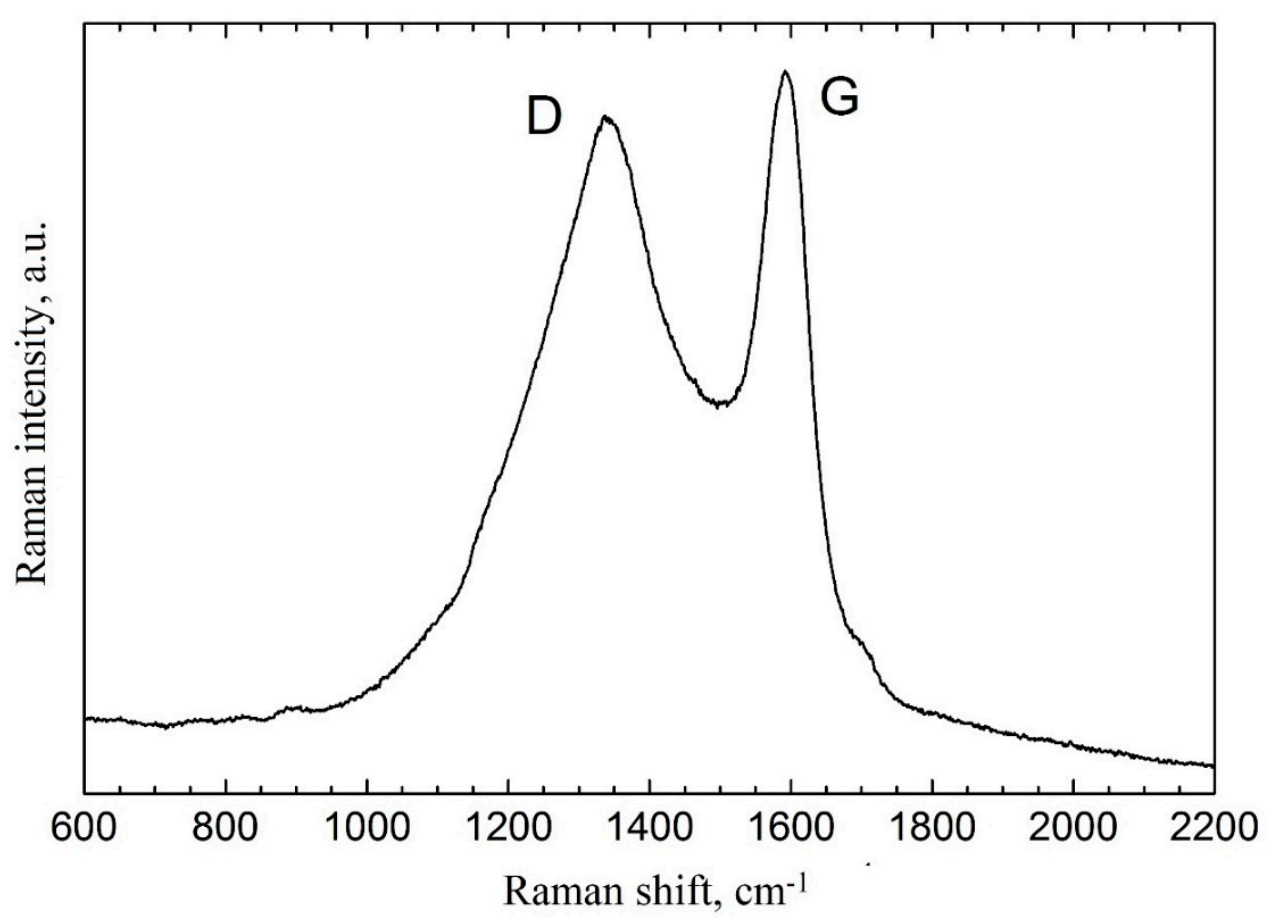

Figure 2. The Raman spectrum of the MC sample.

Our Raman results are compatible with those reported by Hurtado et al. [27], Zhu et al. [32], Gentoiu et al. [33], and Nasri-Nasrabadi et al. [34], regarding systems containing micro/nano structured carbon. More specifically, Zhu et al. [32] synthesized carbon nanostructures on Ni-plated commercial hard metal YG6 (WC-6 wt\% Co) using a simple ethanol diffusion flame technique. It was found that the deposition duration caused both a higher quality and degree of graphitization of flame deposited carbon nanostructures. Gentoiu et al. [33] synthesized carbon nanomaterials via injection of acetylene and hydrogen into an argon plasma. At $200^{\circ} \mathrm{C}$, the production of vertical aligned carbon nanotubes was found due to plasma activation. At $300-400{ }^{\circ} \mathrm{C}$, only the presence of amorphous carbon nanoparticles was detected. Rising temperature resulted in the transformation of amorphous carbon into graphite with simultaneous production of carbon nanowalls, which took place at temperatures higher than $500{ }^{\circ} \mathrm{C}$. The obtained carbon nanomaterials were characterized by a desirable quality of thickness, H:C ratio, and degree of graphitization. Finally, Nasri-Nasrabadi et al. [34] prepared a nanogrooved surface carbon microtube over polymeric matrices using the sonochemical technique. It was indicated that nanogrooving led to an increase of the cohesion between carbon microtubes and polymer matrix via the formation of bonding sites followed by the generation of networks with polymer chains. This simplifies the extrusion processing of carbon tubes. The modified microtubes were characterized by a high surface area and extruded homogeneity. Carbon tubes obtained by this method can be helpful when producing composite solutions of high rheological stability that allows for the omission of time requirements during the extrusion procedure. 


\subsection{ANFO and Non-Ideal Explosive Characteristics}

In all studied samples (Figure 3), IR bands at $3230-2852 \mathrm{~cm}^{-1}$ were a result of both an asymmetric stretching and an asymmetric deformation vibration of $\mathrm{NH}_{4}{ }^{+}$. The weak band at $1753 \mathrm{~cm}^{-1}$ was assigned to the stretching vibration and in-plane deformation of nitrate anions or the combination of an asymmetric deformation of ammonium cations. Apparent signals at 1410 and $1290 \mathrm{~cm}^{-1}$ demonstrated the degenerate deformation of $\mathrm{NH}_{4}{ }^{+}$along with the stretching vibration of $\mathrm{NO}^{3-}$. The maxima at 1041 and $825 \mathrm{~cm}^{-1}$ reflected a symmetric in-plane stretching and an out-of-plane deformation of $\mathrm{NO}^{3-}$, respectively [35-37].

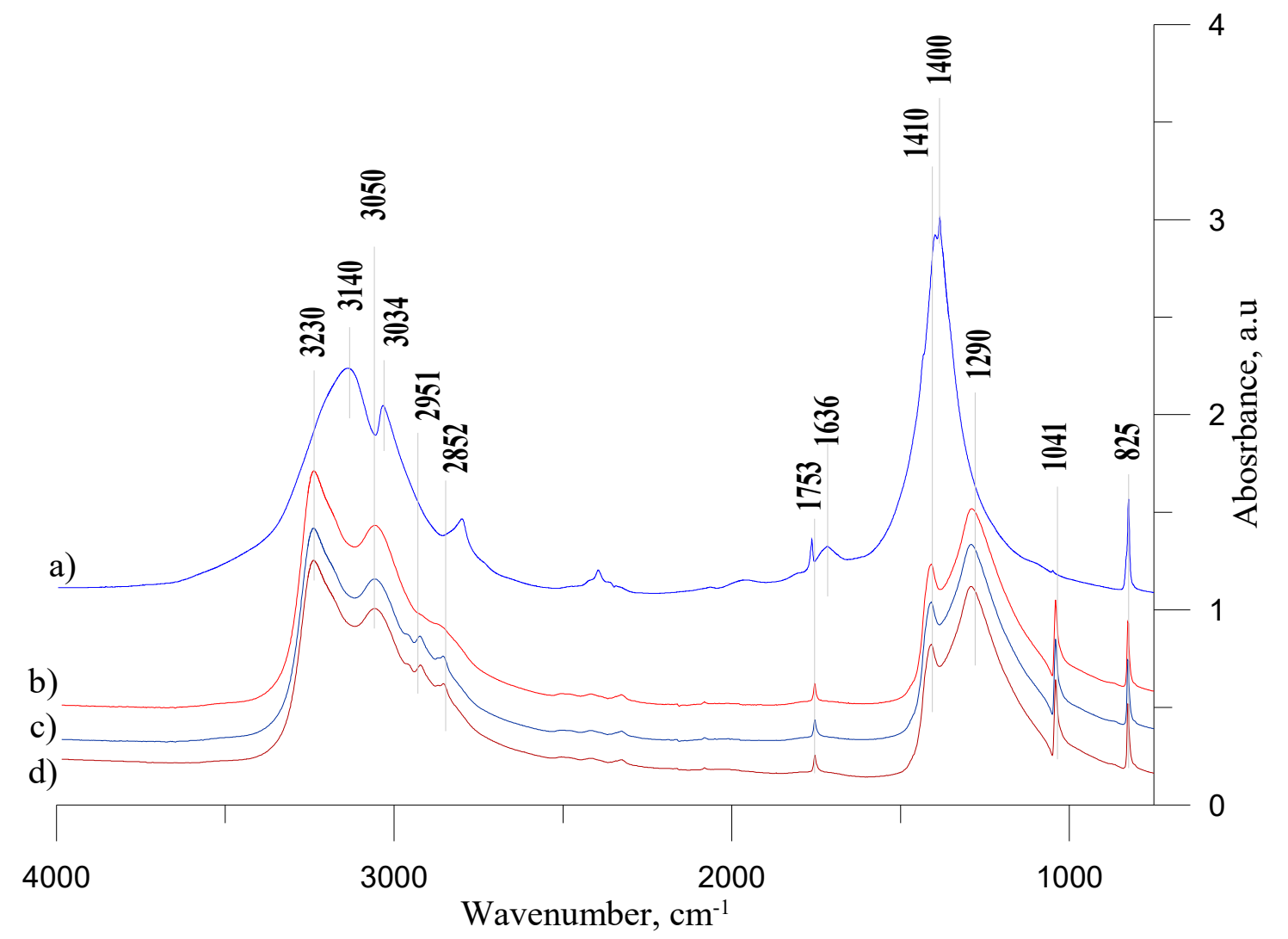

Figure 3. FT-IR spectra of: (a) ANFO, (b) AN-PP, (c) non-ideal explosive with ca. $1.0 \%$ of MC, and (d) non-ideal explosive with ca. 3.0\% of MC.

Introducing FO generated the band at $1636 \mathrm{~cm}^{-1}$, which corresponded with the literature regarding nitration reaction in fuel oils. In the present case, it arose from the reaction with ammonium nitrate already in the mixture preparation phase.

Introducing both concentration combinations $(1 \%$ or $3 \%$ ) of microstructured charcoal into ammonium nitrate led to a slight increase of the bands at 2951 and $2852 \mathrm{~cm}^{-1}$ assigned to stretching vibrations of $-\mathrm{CH}_{2}$ - and $-\mathrm{CH}_{3}$ [38]. These bands are the characteristics of the aliphatic branches at the edges of the pyrolysis-based carbon materials. They are useful to confirm the presence of carbon and its relatively preserved characteristics within the explosive mixture. The rest of the bands attributed to FO probably overlapped with the bands originating from AN skeletal vibrations. From the FT-IR analysis, we can conclude that adding MC did not affect the ANFO structure.

The analysis of XRD patterns confirms the presence of a crystalline AN phase in the studied samples (Figure 4, profiles a-d). According to the literature, the crystalline AN is represented by the IV phase and is characterized by the $\mathrm{P}_{\mathrm{mmm}}$ space group, as well as the orthorombic crystal system $[39,40]$. The diffraction peaks at $2 \theta=18^{\circ}, 22^{\circ}, 24^{\circ}, 29^{\circ}, 31^{\circ}, 33^{\circ}, 36^{\circ}$, and $40^{\circ}$ correspond to the 
(100), (011), (110), (111), (002), (020), (102), (201), (112), (211), and (210) reflections in ANFO crystallites, respectively $[1,41,42]$.

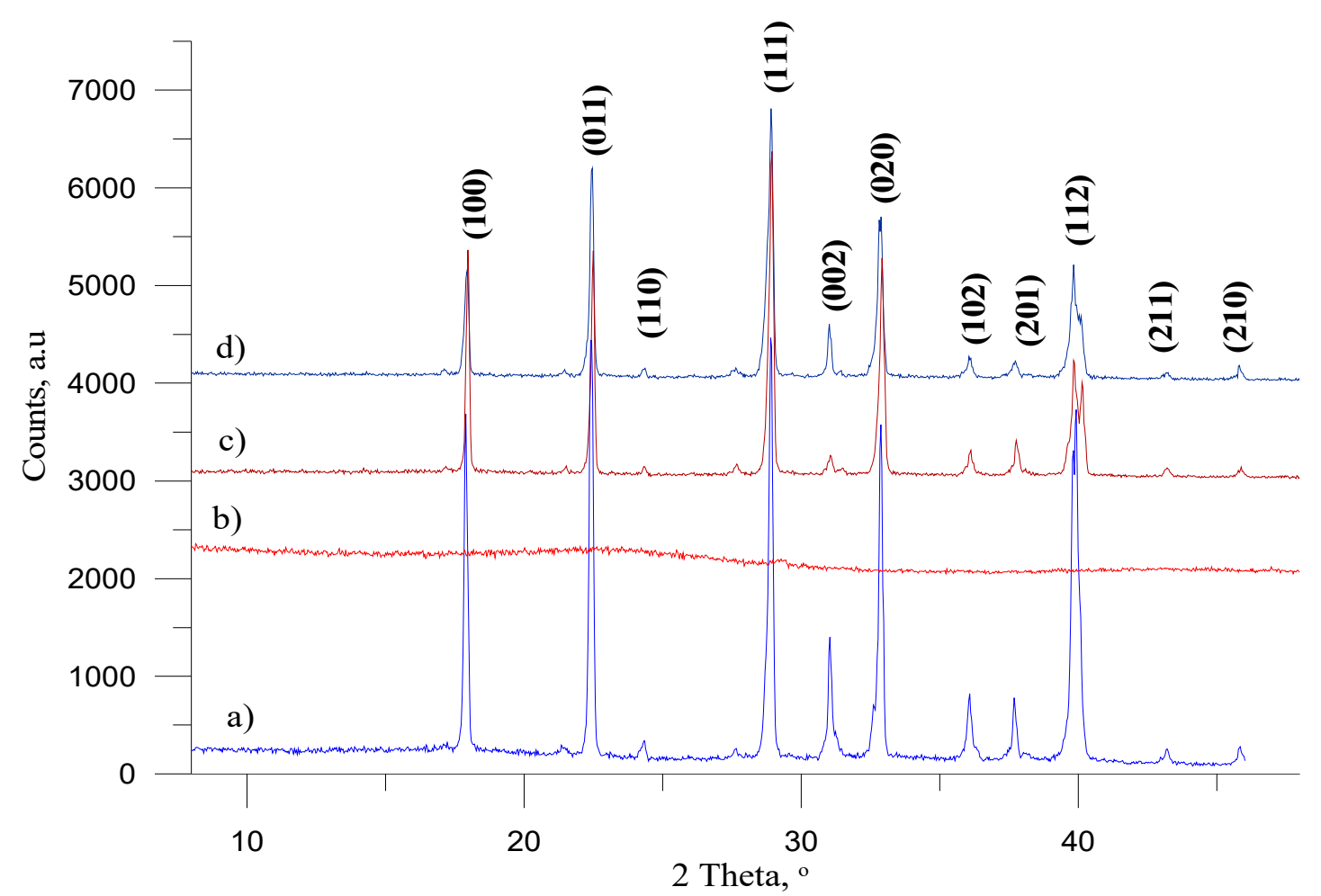

Figure 4. XRD profiles of: (a) ANFO, (b) MC, (c) non-ideal explosive with ca. $1.0 \%$ of MC, and (d) non-ideal explosive with ca. $3.0 \%$ of MC.

Adding MC into ANFO (Figure 4c,d) caused intensity changes in XRD reflections without any apparent shift. Different observations were reported by $\mathrm{Xu}$ et al. [41], who investigated the influence of adding organic potassium salts on the phase stability of AN. They indicated that the application of additives had a strong impact on AN since a phase transition takes place via polar groups forming new hydrogen bonds, which influenced the interaction between ammonium and nitrate ions. From the results reported by $\mathrm{Xu}$ et al. [41], we concluded that introducing additives into the AN structure led to more pronounced structural changes, and hence the appearance of the corresponding XRD patterns, with respect to the bare AN. However, in the case of our ANFO-based samples, it is apparent that their structure was preserved and all prepared materials were characterized by high crystallinity.

The crystal surface of ammonium nitrate porous prill was characterized by a large number of surface deformations. Some of the cracks on the crystal surfaces merged and created small cavities. The crystal surface of the prill was wrinkled and highly porous [1,2,43-45]. The addition of fuel oil (Figure 5a,b) indicated that all surface deformations of ammonium nitrate prill were filled with FO. FO was then absorbed by the pores present both on the surface and in the prill's cross-section. Pores in the case of ANFO were considered to act as a hot spot due to shock wave propagation. Moreover, the compression that appeared during shock wave propagation provided the local increase of temperature and pressure that resulted in easier detonation propagation. Miyake et al. [2] indicated that the formation of the hot spot is influenced by the size and volume of the pore, which exists after mixing with oil. They concluded that the pore is relatively small, the oil is restrained from permeating into the particle because of the surface tension, and, subsequently, the rest of the voids could act as hot spots [2]. FO did not dribble from ammonium nitrate (Figure 5a,b). Adding MC into ANFO did not change the morphology of the sample (Figure $5 \mathrm{c}, \mathrm{d}$ ). Fuel oil, similar to pure ANFO, filled all prill surface deformations. However, Figure $5 \mathrm{c}$ indicates the presence of both $\mathrm{FO}$ and microstructured 
charcoal fines on the prill's crystal surface. A small amount of MC powder could be a result of grinding during the mixing process. As in the case of ammonium nitrate, the MC surface was filled with FO (Figure 5e). FO should be absorbed by the porous MC (Figure 5f). FO did not dribble from the surface of non-explosive samples when MC was added.

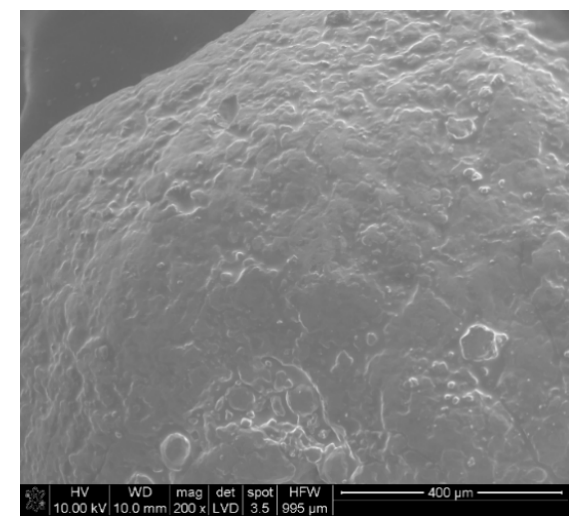

(a)

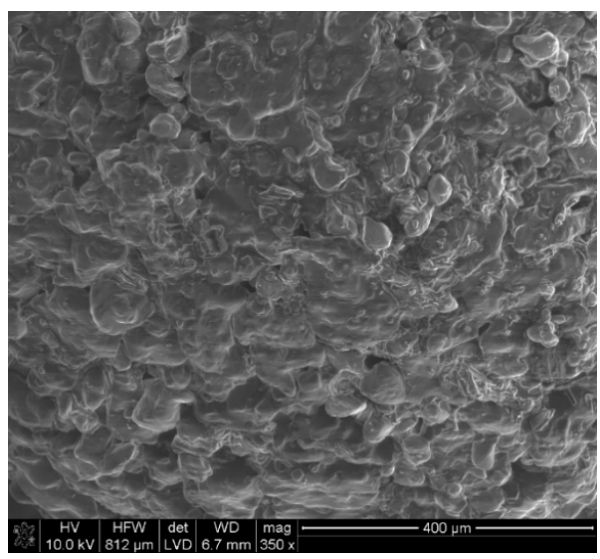

(c)

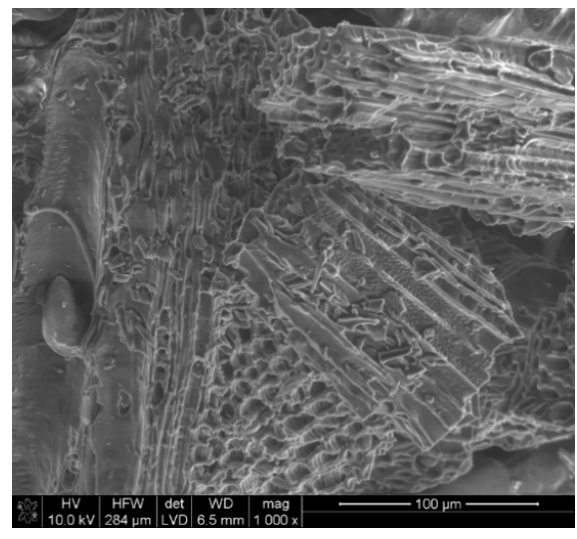

(e)

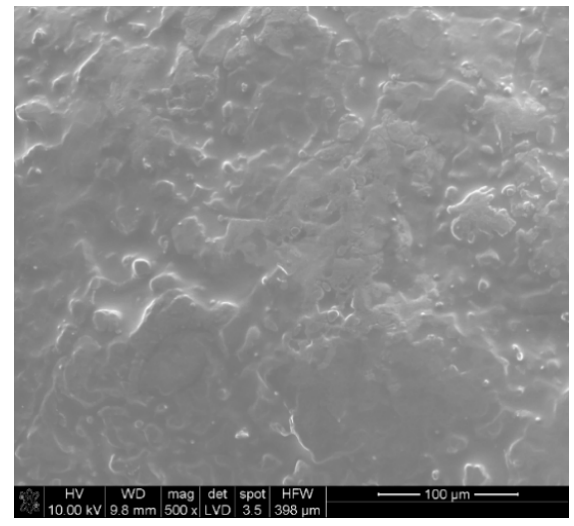

(b)

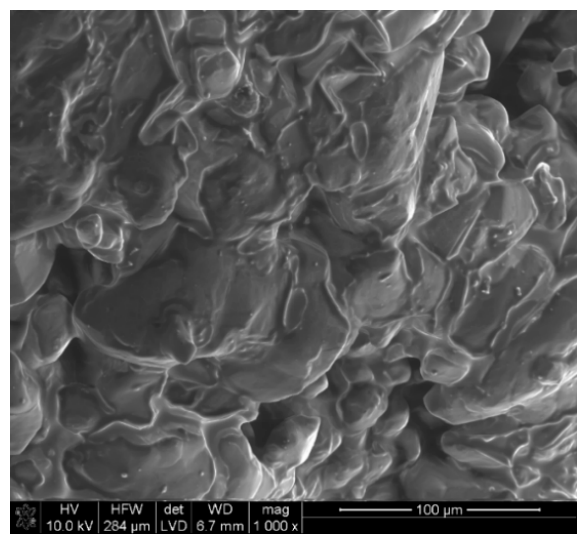

(d)

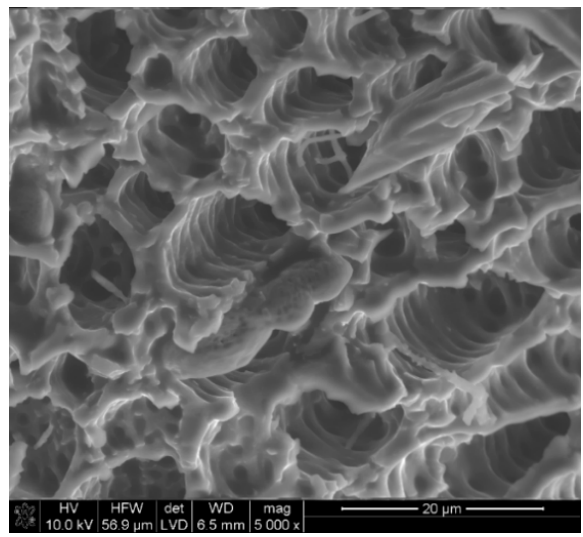

(f)

Figure 5. SEM images of (a) ANFO at 200× magnification, (b) ANFO at 500 $\times$ magnification, (c) non-ideal explosive with $1 \%$ of MC at 350× magnification, (d) non-ideal explosive with $3 \%$ of MC at $1000 \times$ magnification, (e) MC in non-ideal explosive at 1000× magnification, and (f) MC in non-ideal explosive at $5000 \times$ magnification. 
Table 2 sumarizes the calculated blasting properties and indicates MCs potential influence on the non-ideal explosive properties. Adding MC to the non-ideal explosive composition should cause a decrease in explosive density. This could explain the differences in densities between MC (density is lower in comparison to the fuel component) and FO. The intensity decrease should result to a potential decrease of the velocity of detonation (VOD). Moreover, a decrease of energy with increasing MC content should probably result in a decrease of enthalpy, which may influence critical diameter and explosive sensitivity. This means that when MC content increases, the non-ideal explosive should be less sensitive expected theoretically expected, and thus it should require higher heat of explosion from the primer. Furthermore, the performed simulations show that the enthalpy decreases with MC addition. However, despite this fact, MC should combust behind the reaction front. This can be explained by chemical reaction model in non-ideal types of explosive materials, where each individual component of an explosive material can be characterized by the limited or even lack of blasting ability [46]. In normal conditions, when the inert component of a high standard enthalpy of formation is added to the explosive composition, an increase in detonation temperature and pressure should take place. In this scenario, the rise of temperature appears until the additive component is completely burnt near the Chapman-Jouguet plain. A further decrease of temperature and pressure should be followed by a decrease in the VOD, which can be explained by an increased active surface of the inert component. An increased surface should cause an increase in heat transfer and an increase in the chemical reaction surface, or a decrease in initiation induction time. Hence, the decreased detonation pressure and temperature (Table 2) should be explained by the increase of the chemical reaction surface and the lowering of the initiation induction time. Moreover, the presence of a carbon additive in the form of MC should shift the oxygen balance towards negative values due to the replacement of hydrogen atoms from FO. In other words, an additional content of carbon monoxide and soot can appear in the post-blast fumes as the result of a negative oxygen balance. These decomposition reaction products should further influence the afterburning effect as secondary reactions that should lead to an increase in detonation pressure [47]. Salzano and Basco have indicated that the afterburning combustion of black powder enables the production level of energy comparable to TNT afterburning energy [47]. The afterburning effect was not included in the ZMWCyw software. Moreover, owing to the specific properties of the MC surface, it is expected that the MC content should influence $\mathrm{CO}_{\mathrm{x}}$ and $\mathrm{NO}_{\mathrm{x}}$ volume in the post-blast fumes, which may humper the afterburning effect.

Table 2. Average velocity of detonation (VOD) for the investigated samples.

\begin{tabular}{lccc}
\hline \multicolumn{1}{c}{ Parameters } & Sample 1 & Sample 2 & Sample 3 \\
\hline Enthalpy, kJ kg ${ }^{-1}$ & -4287 & -4269 & -4232 \\
Detonation pressure, $\mathrm{MPa}$ & 2785 & 2740 & 2799 \\
Detonation temperature, K & 2701 & 2675 & 2593 \\
Heat of explosion, $\mathrm{kJ} \mathrm{kg}$ & 4012 & 3922 & 3695 \\
Strength of explosion. & 976 & 957 & 911 \\
Post-blast volume, $1 \mathrm{~kg}^{-1}$ & 986 & 977 & 959 \\
Density, $\mathrm{kg} \mathrm{m}^{-1}$ & 823 & 821 & 818 \\
\hline
\end{tabular}

Moreover, based on the potential blasting properties presented in Table 2, it can be observed that the decrease of detonation temperature and pressure was followed by a drop in explosion heat, post-blast volume, and explosive strength. This influence can be explained by the conversion of mass and momentum equations that represent relations between detonation pressure, velocity of detonation, and post-blast volume that further affects the Chapman-Jouguet plain. Furthermore, the Hugoniot's equations indicated an equilibrium state being independent of the explosive density or density of the post-blast fumes, confirming the potential drop of velocity of detonation. 


\section{Conclusions}

In this paper, we presented a possible application of microstructured charcoal in an ANFO explosive.

Based on XRD and IR data, we concluded that adding microstructured charcoal (MC) did not alter the structure of the non-ideal explosive materials. The XRD analysis showed that despite the addition of MC, the sample was characterized by high crystallinity.

SEM analysis indicated that there was no influence of charcoal additives on ANFO morphology. The addition of MC behaved like an inert component in a non-ideal explosive composition (e.g., aluminum in aluminized ANFO). From the MC structure, it can be assumed that other than the presence of FO on the MC surface, FO also experienced macro- and mesoporous absorption. In addition, a small amount of MC powder was visible on the AN-PP. The MC powder was probably obtained due to grinding between prill and MC particles during the mixing process.

All morphology analyses showed that MC may be applied as an ANFO component. The addition of MC to ANFO should influence oxygen balance, density of the non-explosive part, and should eventually result in changes to the Chapman-Jouguet plain.

We evaluated blasted parameters based on the ZMWCyw software, which revealed that the addition of MC decreased the heat of explosion, detonation pressure, and detonation reaction. Moreover, the density of the non-ideal explosive decreased when MC content increased. This ideally should result in a lower velocity of detonation. Despite the fact that the blasting parameters decreased, the differences between the expected blasted parameters of regular ANFO and the studied non-ideal explosive samples were negligible. Moreover, the results obtained from the ZMWCyw simulation should be preliminary treated due to the fact that all simulations concerned non-ideal types of explosives.

The present results could link the improvement of mining explosives by adding a widely available and environmentally friendly additive, such as microstructured charcoal. Moreover, it is expected that the unique surface structure of MC should influence the afterburning effect and the concentration of toxic components in post-blast fumes.

Author Contributions: Conceptualization, A.B.; methodology, A.B. and S.G.A.; validation, A.B., S.G.A. and J.A; formal analysis, A.B., S.G.A., J.A. and N.S.; investigation, S.G.A., A.B., Ł.K., M.D., M.T., J.A. and N.S.; resources, A.B., S.G.A. and Ł.K.; writing—original draft preparation, S.G.A., A.B., Ł.K., M.D, M.T., J.A. and N.S.; writing-review and editing, A.B., S.G.A. and Ł.K.; visualization, A.B., S.G.A. and J.A.; supervision, A.B. All authors have read and agreed to the published version of the manuscript.

Funding: The authors wish to thank for financial support from the research no. 16.16.100.215 of The Faculty of Mining and Geoengineering at the AGH University of Science and Technology in Krakow and the Ministry of Scientific and Technological Development of Republic of Srpska and industrial partner "Destilacija" Teslić, for project number 19032/961-152/19.

Conflicts of Interest: The authors wish to confirm that there are no known conflicts of interest associated with this publication and there has been no significant financial support for this work that could have influenced its outcome.

\section{References}

1. Biessikirski, A.; Kuterasiński, Ł. Research on Morphology and Topology of ANFO Based on Various Types of Oxygen Component; Wydawnictwa AGH: Kraków, Poland, 2018.

2. Miyake, A.; Takahara, K.; Ogawa, T.; Ogata, Y.; Wada, Y.; Arai, H. Influence of physical properties of ammonium nitrate on the detonation behavior of ANFO. J. Loss. Prev. Process Ind. 2001, 14, 533-538. [CrossRef]

3. Zygmunt, B. Detonation Parameters of Mixtures Containing Ammonium Nitrate and Aluminium. Cent. Eur. J. Energ. Mater. 2009, 6, 57-66.

4. Oxley, J.C.; Smith, J.L.; Rogers, E.; Yu, M. Ammonium Nitrate: Thermal Stability and Explosivity Modifiers. Thermochim. Acta 2002, 384, 23-45. [CrossRef]

5. Oxley, J.C.; Smith, J.L.; Wang, W. Compatibility of Ammonium Nitrate with Monomolecular Explosives 2. Nitroarenes12. J. Phys. Chem. 1994, 98, 3901. [CrossRef] 
6. Brower, K.R.; Oxley, J.C.; Tewari, M. Evidence for Homolytic Decomposition of Ammonium Nitrate at High Temperature. J. Phys. Chem. 1989, 93, 4029. [CrossRef]

7. Wada, Y.; Hori, K.; Arai, M. Combustion Mechanism of Mixtures of Guanidine Nitrate, Ammonium Nitrate and Basic Copper Oxide. Sci. Technol. Energ. Mater. 2010, 71, 83.

8. Marshall, M.; Jimmie, C.O. (Eds.) Aspects of Explosives Detection; Elsevier: Amsterdam, The Netherlands, 2009.

9. Sinditskii, V.P.; Egorshev, V.Y.; Levshenkov, A.I.; Serushkin, V.V. Ammonium Nitrate: Combustion Mechanism and the Role of Additives. Propellants Explos. Pyrotech. 2005, 30, 269-280. [CrossRef]

10. Gunawan, R.; Zhang, D. Thermal stability and kinetics of decomposition of ammonium nitrate in the presence of pyrite. J. Hazard. Mater. 2009, 165, 751-758. [CrossRef]

11. Deribas, A.A.; Kudinov, V.M.; Matveenkov, F.I.; Simonov, V.A. Effect of initial parameters on the process of wave formation in explosive welding. Combust. Explos. Shock Waves 1967, 3, 344-348. [CrossRef]

12. Miyake, A.; Ohtagaki, Y.; Abe, T.; Wada, Y.; Nakayama, Y.; Ogawa, T. Experimental Determination of the Detonation Front Curvature of Non-Ideal Explosive ANFO. Mater. Sci. Forum 2004, 465, 181-184. [CrossRef]

13. Maranda, A.; Gałęzowski, D.; Papliński, A. Investigations on detonation and thermochemical parameters of aluminized ANFO. J. Energ. Mater. 2003, 21, 1-14. [CrossRef]

14. Maranda, A.; Paszula, J.; Zawadzka-Małota, I.; Kuczyńska, B.; Witkowski, W.; Nikolczuk, K.; Wilk, Z. Aluminum powder influence on ANFO detonation parameters. Cent. Eur. J. Energ. Mater. 2011, 8, $279-293$.

15. Babrauskas, V.; Leggett, D. Thermal decomposition of ammonium nitrate. Fire Mater. 2020, 44, $250-268$. [CrossRef]

16. Reiset, J.; Millon, E. Ueber die durch Contact bewirkten chemischen Erscheinungen. J. Prakt. Chem. 1843, 29, 365-371. [CrossRef]

17. Izato, Y.; Miyake, A.; Date, S. Combustion characteristics of ammonium nitrate and carbon mixtures based on a thermal decomposition mechanism. Propell. Explos. Pyrotech. 2013, 38, 129-135. [CrossRef]

18. Hussain, G.; Rees, G.J. Combustion of $\mathrm{NH}_{4} \mathrm{NO}_{3}$ and carbon based mixtures. Fuel 1993, 72, 1475-1479. [CrossRef]

19. Lurie, B.A.; Chang, L. Kinetics and mechanism of thermal decomposition of ammonium nitrate powder under the action of carbon black. Combust. Explos. Shock Waves 2000, 36, 607-617. [CrossRef]

20. Brill, T.B.; Brush, P.J.; Patil, D.G. Thermal decomposition of energetic materials 58. Chemistry of ammonium nitrate and ammonium dinitramide near the burning surface temperature. Combust. Flame 1993, 92, 186.

21. Glazkova, A.P.; Kazarova, Y.A.; Savel'ev, A.V. Oxidation of carbon by nitrites and nitrates. Combust. Explos. Shock Waves 1983, 19, 308-314. [CrossRef]

22. Miyake, A.; Kobayashi, H.; Echigoya, H.; Ogawa, T. Combustion and ignition properties of ammonium nitrate and activated carbon mixtures. Int. J. Energ. Mater. Chem. Propuls. 2009, 8, 411-419. [CrossRef]

23. Izato, Y.I.; Miyake, A.; Echigoya, H. Influence of physical properties of carbon on the detonation behaviour of ammonium nitrate and carbon mixtures. In Proceedings of the Seventh International Symposium on Hazards, Prevention, and Mitigation of Industrial Explosions, St. Petersburg, Russia, 7-11 July 2008; pp. 255-259.

24. Biessikirski, A.; Wądrzyk, M.; Janus, R.; Biegańska, J.; Jodłowski, G.; Kuterasiński, Ł. Study on fuel oils used in ammonium nitrate-based explosives. Przem. Chem. 2018, 97, 457-462.

25. BN-80/6091-42. Górnicze Materiały Wybuchowe. Obliczanie Parametrów Użytkowych; Zakłady Tworzyw Sztucznych ERG: Tychy-Bierun Stary, Poland, 1981.

26. Wang, L.; Ago, M.; Borghei, M.; Ishaq, A.; Papageorgiou, A.C.; Lundahl, M.; Rojas, O.J. Conductive Carbon Microfibers Derived from Wet-Spun Lignin/ Nanocellulose Hydrogels. ACS Sustain. Chem. Eng. 2019, 7, 6013-6022. [CrossRef]

27. Hurtado, R.B.; Calderón-Ayala, G.; Cortez-Valadez, M.; López Torres, R.; Berrellez-Reyes, F.; Flores-Acosta, M. Efficient synthesis of carbon microtubes-gold nanoparticles composite: Optical and micro-analytical study. Appl. Phys. A 2019, 125, 844. [CrossRef]

28. Wu, J.B.; Lin, M.L.; Cong, X.; Liua, H.N.; Tan, P.H. Raman spectroscopy of graphene-based materials and its applications in related devices. Chem. Soc. Rev. 2018, 47, 1822-1873. [CrossRef] [PubMed]

29. Ferreira, E.M.; Moutinho, M.V.; Stavale, F.; Lucchese, M.; Capaz, R.B.; Achete, C.; Jorio, A. Evolution of the Raman spectra from single-, few-, and many-layer graphene with increasing disorder. Phys. Rev. B Condens. Matter Mater. Phys. 2010, 82, 125429. [CrossRef] 
30. Yang, D.; Velamakanni, A.; Bozoklu, G.; Park, S.; Stoller, M.; Piner, R.D.; Stankovich, S.; Jung, I.; Field, D.A.; Ventrice, C.A. Chemical Analysis of Graphene Oxide Films after Heat and Chemical Treatments by X-ray Photoelectron and Micro-Raman Spectroscopy. Carbon 2009, 47, 145-152. [CrossRef]

31. Zhang, L.; Shi, Z.; Wang, Y.; Yang, R.; Shi, D.; Zhang, G. Catalyst-free growth of nanographene films on various substrates. Nano Res. 2011, 4, 315-321. [CrossRef]

32. Zhu, H.; Kuang, T.; Zhu, B.; Lei, S.; Liu, Z.; Ringer, S.P. Flame synthesis of carbon nanostructures on Ni-plated hardmetal substrates. Nanoscale Res. Lett. 2011, 6, 331. [CrossRef]

33. Gentoiu, M.; Betancourt-Riera, R.; Vizireanu, S.; Burducea, I.; Marascu, V.; Stoica, S.D.; Bita, B.I.; Dinescu, G.; Riera, R. Morphology, Microstructure, and Hydrogen Content of Carbon Nanostructures Obtained by PECVD at Various Temperatures. J. Nanomater. 2017, 1-8. [CrossRef]

34. Nasri-Nasrabadi, B.; Kaynak, A.; Komeily-Nia, Z.; Adams, S.D.; Li, J.; Kouzani, A.Z. Surface nanogrooving of carbon microtubes. Sci. Rep. 2018, 8,1-8. [CrossRef]

35. Wu, H.B.; Chan, M.N.; Chan, C.K. FTIR Characterization of Polymorphic Transformation of Ammonium Nitrate. Aerosol Sci. Technol. 2007, 41, 581-588. [CrossRef]

36. Available online: https://webbook.nist.gov/cgi/cbook.cgi?Name=ammonium + nitrate\&Units=SI\&cIR=on\#Refs (accessed on 1 January 2020).

37. Biessikirski, A.; Kuterasiński, Ł.; Pyra, J.; Dworzak, M. Comparison of properties of ammonium nitrates used for production of fertilizers and explosive materials. Przem. Chem. 2016, 95, 1381-1384.

38. Steele, B.A.; Oleynik, I.I. New crystal phase ammonium nitrate: First-principles prediction and characterization. In Proceedings of the AIP Conference Proceedings, Tampa Bay, FL, USA, 14-19 June 2015; Volume 1793, p. 130008.

39. Chien, W.M.; Chandra, D.; Franklin, J.; Rawn, C.J.; Helmy, A.K. X-ray Diffractometry studies and lattice parameter calculation on KNO3-NH4NO3 solid solutions. In Proceedings of the International Centre for Diffraction Data, Philadelphia, PA, USA, 20-25 June 2004.

40. Ferg, E.; Masalova, I. Using PXRD to Investigate the Crystallization of Highly Concentrated Emulsions of $\mathrm{NH}_{4} \mathrm{NO}_{3}$. S. Afr. J. Chem. 2011, 64, 7-16.

41. Xu, Z.X.; Fu, X.Q.; Wang, Q. Phase Stability of Ammonium Nitrate with Organic Potassium Salts. Cent. Eur. J. Energ. Mater. 2016, 13, 736-754. [CrossRef]

42. Vargeese, A.A.; Joshi, S.S.; Krishnamurthy, V.N. Effect of method of crystallization on the IV-III and IV-II polymorphic transitions of ammonium nitrate. J. Hazard. Mater. 2009, 161, 373-379. [CrossRef]

43. Lotspeich, E.; Petr, V. The characterization of ammonium nitrate mini-prills. In Dynamic Behavior of Materials Proceedings of the 2014 Annual Conference on Experimental and Applied Mechanics; Song, B., Casem, D., Kimberley, J., Eds.; Springer: Cham, Switzerland, 2015; Volume 1, pp. 319-325.

44. Biessikirski, A.; Kuterasiński, Ł.; Dworzak, M.; Pyra, J.; Twardosz, M. Comparison of structure, morphology and topography of fertilizer-based explosives applied in the mining industry. Microchem. J. 2019, 144, $39-44$. [CrossRef]

45. Viktorov, S.D.; Frantov, A.E.; Lapikov, I.N.; Andreev, V.V.; Starshinov, A.V. Effect of microstructure of ammonium nitrate granules on the detonability of composite propellants based on it. Combust. Explos. Shock Waves 2016, 52, 727-731. [CrossRef]

46. Maranda, A. Influence of aluminium chemical activity on detonation parameters of composite explosives containing aluminium powders (CX-AL). Wiad. Chem. 2001, 55, 353-375.

47. Salzano, E.; Basco, A. Comparision of the explosion thermodynamics of TNT and black powder using Le Chatelier diagrams. Propellants Explos. Pyrotech. 2012, 37, 724-731. [CrossRef]

(C) 2020 by the authors. Licensee MDPI, Basel, Switzerland. This article is an open access article distributed under the terms and conditions of the Creative Commons Attribution (CC BY) license (http://creativecommons.org/licenses/by/4.0/). 